\title{
Fabrication of Superhydrophobic Metal Surfaces with Self-Assembled Monolayers of Silane Derivatives Having Inter-Hydrogen Bonding
}

\author{
Yeonhwa Park, Moonhee Han, and Yonghyun Ahn* \\ Department of Chemistry, GRRC, Dankook University, Yongin 448-701, Korea. *E-mail: yhahn@dankook.ac.kr \\ Received November 30, 2010, Accepted January 21, 2011
}

Key Words : Superhydrophobicity, Wettability, Urea-silane, SAMs, Cupper deposition

In recent times, there has been an increasing interest in superhydrophobic surfaces, as these surfaces have applications in various fields. ${ }^{1,2}$ Many different methods for the fabrication of superhydrophobic surfaces have been reported; these include a sol-gel method, ${ }^{3-6}$ chemical etching, ${ }^{7,8}$ the application of a polymer, ${ }^{9-13}$ electrodeposition, ${ }^{14}$ and the use of self-assembled monolayers (SAMs) of organic materials. ${ }^{15-18}$

SAMs of organic materials have conventionally been used for surface modification. It is possible to modify the physical and chemical properties of a solid surface by coating the surface with self-assembled organic layers (SAMs). The wettability of alkylsilane SAMs is dependent on the degree of self-assembly and the roughness of the surface; highly ordered coatings of alkylsilane molecules increase the hydrophobicity of the coated surface considerably.

$n$-Alkyltriethoxysilane was hydrolyzed and polymerized to produce a self-assembled alkylsilane coating with a low surface energy. A hydrophilic surface coated with this self-assembled alkylsilane coating becomes hydrophobic because the surface is fully grafted by the molecules of SAM, which results in the $\mathrm{CH}_{3}$ and $\mathrm{CH}_{2}$ groups being exposed. The wettability of an alkylsilane-coated surface is defined by the relative contributions of groups atop. The formation mechanism of alkylsilane SAMs is as follows: first, alkyl triethoxysilane is hydrolyzed by $\mathrm{H}_{2} \mathrm{O}$, which results in the formation of alkylsilanol. The $\mathrm{OH}$ groups of alkylsilanol condense to form ether linkages between $\mathrm{Si}$ and the surface. Depending on the reaction conditions, wellordered molecules (A), collapsed molecules (B), and lying down molecules (C) can be formed (Fig. 1). ${ }^{19}$

Thus far, SAMs of alkane thiols ${ }^{20}$ and long-chain fatty acids $^{21}$ have been fabricated. Fluorinated alkyl-silane which is very popular in wettability studies has been used to coat solid surfaces in order to obtain superhydrophobic surfaces. ${ }^{22,23}$ When SAMs are formed on a surface, the alkyl chains in the monolayer interact with each other only in a hydrophobic manner.

In this study, we introduced an urea group in organo-silane derivatives to obtain, in addition to hydrophobic interaction, improved interaction between the molecules via hydrogen bonds (Fig. 1). This study describes the synthesis of aryland alkyl-urea silanes and their application to the modification of a cupper deposited surface with the objective of obtaining a superhydrophobic surface.
(A)

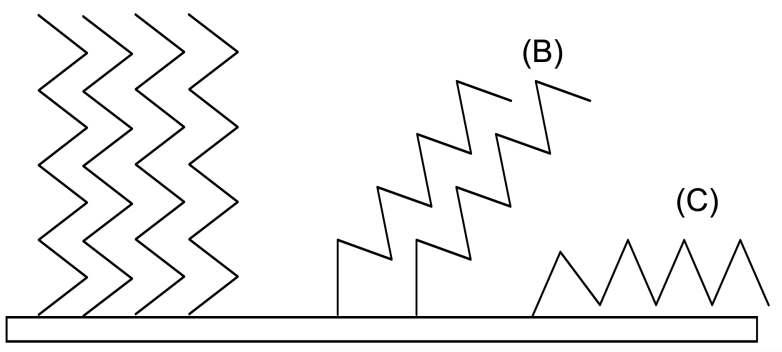

(a)

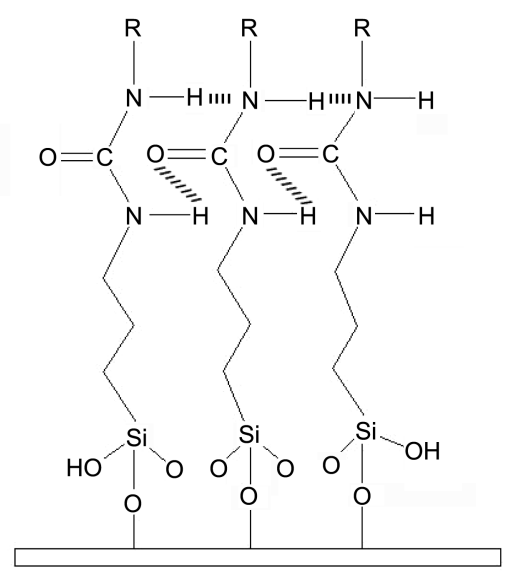

(b)

$$
\mathrm{R}=\mathrm{CH}_{3} \mathrm{CH}_{2} \mathrm{CH}_{2} \mathrm{CH}_{2} \mathrm{CH}_{2} \mathrm{CH}_{2}
$$

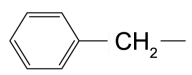

Figure 1. (a) Possible conformation of alkyl silane with the surface. (b) Hydrogen bonds between molecules in the SAM. 


\section{Experimental}

Instrumentation. The water contact angles of the cupper deposited magnesium surface were measured using a contact angle analyzer (Phoenix 300, Surface Electro Optics) at ambient temperature. The morphology of the surface was observed by FE-SEM (Hitachi S4300, Hitachi Inc.). The XPS spectrum of the surface was obtained using a spectrometer (MultiLab 2000, Thermo VG Scientific). External Fourier transform infrared (FTIR) spectra were obtained using a spectrometer (Travel IR, Sens IR technologies) with a KBr plate. The NMR spectra were obtained using a NMR spectrometer (Avance 600, Bruker).

General Procedure for Synthesis of 1-\{3-(Triethoxysilyl)\}propyl-3-phenethyl-urea (1): 2-Phenethylamine (3.4 g, $28 \mathrm{mmol})$ was dissolved in toluene $(20 \mathrm{~mL})$ and triethylamine $(2.8 \mathrm{~g}, 28 \mathrm{mmol})$ was added to this solution. To this reaction mixture was added 3-(triethoxysilyl)propyl isocyanate $(6.9 \mathrm{~mL}, 28 \mathrm{mmol})$ and then the mixture was refluxed for $20 \mathrm{~h}$. The mixture was then cooled to room temperature, and the solvent was evaporated. The product was purified by vacuum distillation. Yields $9.8 \mathrm{~g}(95 \%) .{ }^{1} \mathrm{H}$ NMR (600 MHz, $\left.\mathrm{CDCl}_{3}, \mathrm{ppm}\right) \delta$ 7.1-7.3 (m, 5H), 4.5 (bt, $1 \mathrm{H}), 4.3$ (bt, 1H), 3.8 (q, $J=4.1 \mathrm{~Hz}, 6 \mathrm{H}), 3.4$ (q, $J=4 \mathrm{~Hz}$, $2 \mathrm{H}), 3.1(\mathrm{q}, J=4 \mathrm{~Hz}, 2 \mathrm{H}), 2.8(\mathrm{t}, J=4.1 \mathrm{~Hz}, 2 \mathrm{H}), 1.6(\mathrm{~m}$, $2 \mathrm{H}), 1.2(\mathrm{t}, J=4.2 \mathrm{~Hz}, 9 \mathrm{H}), 0.6(\mathrm{t}, J=4.9 \mathrm{~Hz}, 2 \mathrm{H}) .{ }^{13} \mathrm{C} \mathrm{NMR}$ $\left(150 \mathrm{MHz}, \mathrm{CDCl}_{3}\right) \delta$ 7.6, 18.2, 23.5, 36.4, 41.6, 42.9, 58.4, 126.3, 128.5, 128.8, 139.2, 158.0. FT-IR $\left(\mathrm{KBr}, \mathrm{cm}^{-1}\right) 3350$, 3050, 2960, 2900, 1610, 1580, 1230, 1080, 960.

Synthesis of 1-\{3-(Triethoxysilyl)\}propyl-3-hexyl-urea (2): The title compound was prepared from hexylamine (2.8 g, $28 \mathrm{mmol})$, triethylamine (2.8 g, $28 \mathrm{mmol}), 3-$ (triethoxysilyl)propyl isocyanate $(6.9 \mathrm{~mL}, 28 \mathrm{mmol})$ and toluene $(20 \mathrm{~mL})$ according to the general procedure. Yields $8.7 \mathrm{~g}(89 \%) .{ }^{1} \mathrm{H}-\mathrm{NMR}\left(600 \mathrm{MHz}, \mathrm{CDCl}_{3}, \mathrm{ppm}\right) \delta 4.5$ (bt, 1H), 4.4 (bt, 1H), 3.8 (q, $J=4.1 \mathrm{~Hz}, 6 \mathrm{H}), 3.15$ (m, 4H), 1.63 $(\mathrm{m}, 2 \mathrm{H}), 1.48(\mathrm{~m}, 2 \mathrm{H}), 1.3(\mathrm{~m}, 6 \mathrm{H}), 1.24(\mathrm{t}, J=4.1 \mathrm{~Hz}, 9 \mathrm{H})$, $0.88(\mathrm{t}, J=4.2 \mathrm{~Hz}, 3 \mathrm{H}), 0.64(\mathrm{t}, J=4.9 \mathrm{~Hz}, 2 \mathrm{H}) .{ }^{13} \mathrm{C} \mathrm{NMR}$ $\left(150 \mathrm{MHz}, \mathrm{CDCl}_{3}\right) \delta 7.5,14.0,18.3,22.5,23.5,26.5,30.2$, 31.5, 40.6, 42.9, 58.4, 158.2. FT-IR $\left(\mathrm{KBr}, \mathrm{cm}^{-1}\right) 3340,2960$, 2920, 1640, 1585, 1255, 1080, 950.

Fabrication of Superhydrophobic Surface. A magnesium plate was ultrasonically cleaned in ethanol for 5 minutes and deionized water for 10 minutes. The plate was

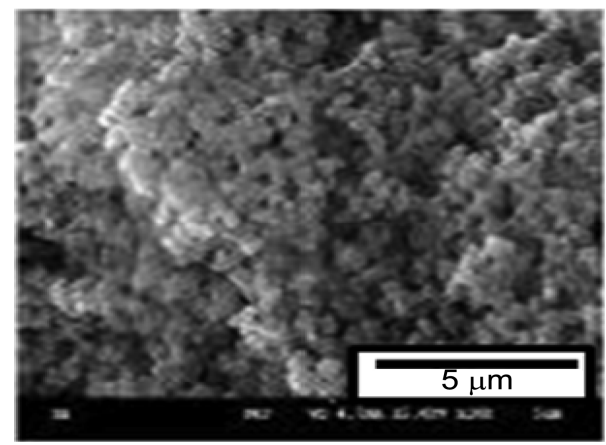

Figure 2. SEM image of $\mathrm{Cu}$ deposited $\mathrm{Mg}$ surface. dried and then immersed in 5\% $\mathrm{HCl}$ solution for $5 \mathrm{~min}$; thereafter, it was rinsed with deionized water and then oven dried at $80{ }^{\circ} \mathrm{C}$ for $24 \mathrm{~h}$. The magnesium plate was immersed in a mixed chemical solution $\left(1.2 \mathrm{~g}\right.$ of $\mathrm{CuSO}_{4} \cdot 5 \mathrm{H}_{2} \mathrm{O}$ and 0.6 $\mathrm{g}$ of hydrazine hydrate in $100 \mathrm{~mL}$ of distilled water) for $4 \mathrm{~h}$ at $80{ }^{\circ} \mathrm{C}$ and then dried overnight at room temperature. The copper deposited plate was immersed in a solution comprising compound $1(0.75 \mathrm{~g})$ in $50 \mathrm{~mL}$ ethanol and $5 \mathrm{~mL}$ of $0.1 \mathrm{~N} \mathrm{HCl}$ for $30 \mathrm{~min}$ and then dried at room temperature for $24 \mathrm{~h}$.

\section{Results and Discussion}

The superhydrophobicity of the surface of a solid material is governed by both the low surface energy material and its geometrical structure of surface. The surface of magnesium is hydrophilic and its contact angle is approximately $58^{\circ}$ for water. In this study, the copper deposited magnesium plate was treated with the silane derivatives. A flat surface can be converted into a rough surface because a material coating of flat surface with low surface energy material showed the water contact angle of less than $120^{\circ} .{ }^{24}$ Figure 2 shows SEM images of the copper deposited on the surface of magnesium plate. The copper particles on the surface vary from $10 \mu \mathrm{m}$ to $50 \mu \mathrm{m}$ in size and valleys can be observed on the surface. After the deposition of copper particles on the surface of the magnesium plate, the surface was modified by hexyl- or phenethyl-urea silane (Fig. 3).

The formation of SAMs on the surface of a metal affects the properties of the metal surface to a significant extent. Interestingly, we found that the contact angles of a surface treated with hexyl-urea silane were almost similar to those of

(a)

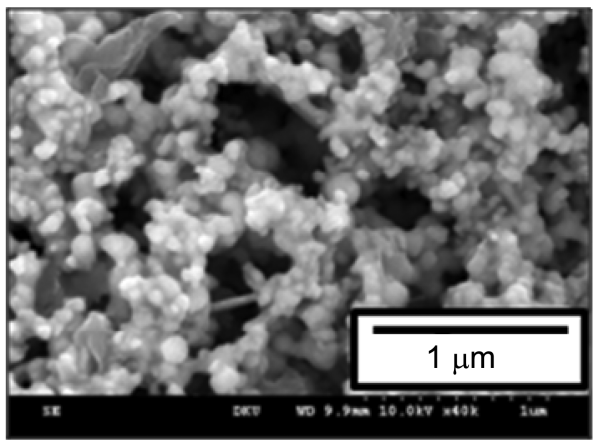

(b)

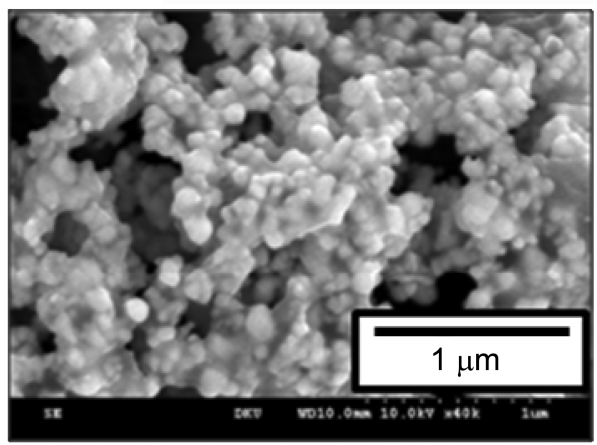

Figure 3. SEM images of $\mathrm{Cu}$ deposited on $\mathrm{Mg}$ surface modified with (a) phenethyl- and (b) hexyl-urea silane. 

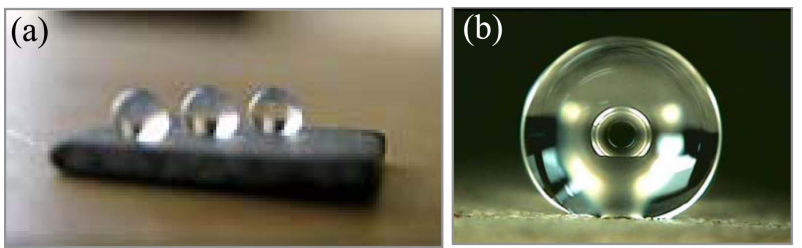

Figure 4. (a) Optical image of water droplets on the $\mathrm{Cu}$ deposited $\mathrm{Mg}$ surface treated with phenethyl-urea silane. (b) Profile of water droplet on surface having a contact angle of $155^{\circ}$.

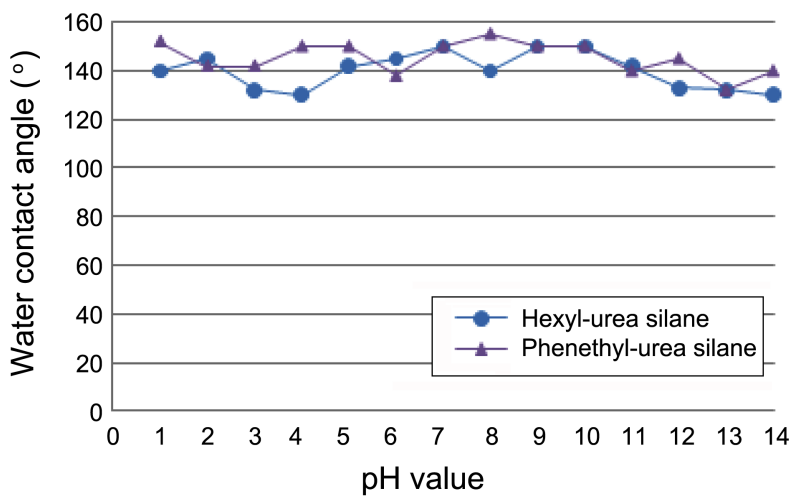

Figure 5. Relationship between $\mathrm{pH}$ and water contact angle on superhydrophobic surfaces.

a surface treated with phenethyl-urea silane, $150^{\circ}$ and $155^{\circ}$, respectively (Fig. 4).

Figure 5 shows the relationship between the $\mathrm{pH}$ value and the water contact angle on the superhydrophobic surfaces. The coated surface showed a high water contact angle, and it was stable over a wide range of $\mathrm{pH}$ values.

The driving force of the formation of SAMs was the interaction between adjacent hydrocarbon moieties (i.e., van der Waals forces). In addition, during the formation of monolayers of hexyl- or phenethyl-urea silane on the surface, hydrogen bond formation occurs (Fig. 6). The hydrogen bonds in the SAMs increase the stability of the coating and prevent the occurrence of collapsed molecules

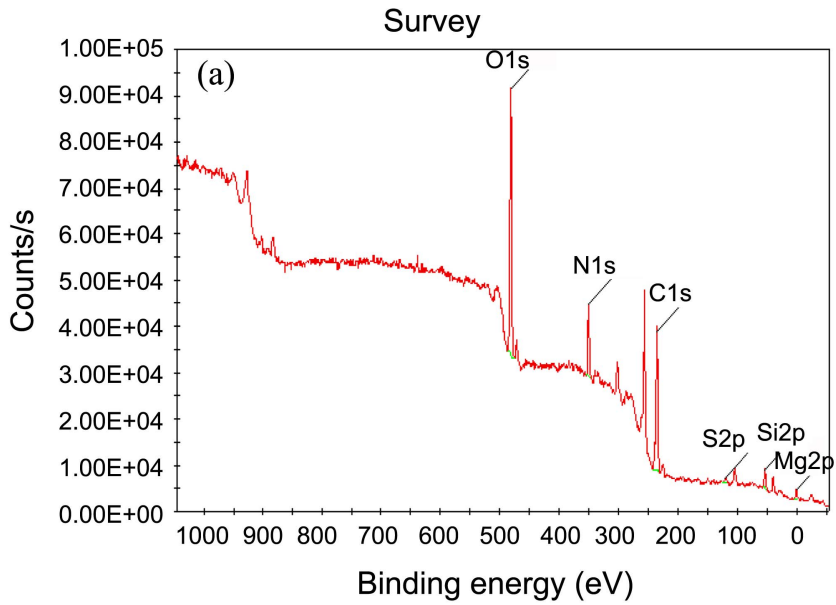

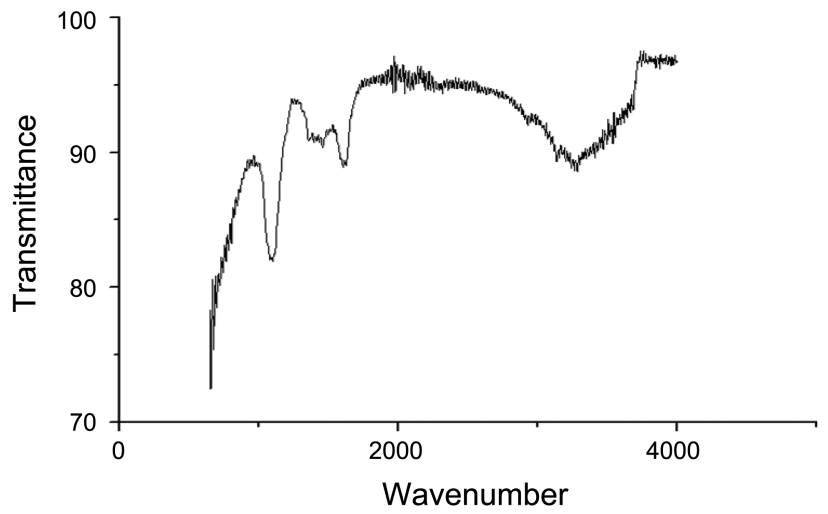

Figure 6. IR spectrum of hexyl-urea silane coating on $\mathrm{Cu}$ deposited Mg plate.

or lying down molecules.

The surface chemical composition was identified by XPS. Figure 7 shows the XPS spectrum of the copper deposited magnesium plate modified by the silane derivatives. The modified surface shows the significant peaks at $284.4 \mathrm{eV}$ and $401.1 \mathrm{eV}$ and corresponding to the $\mathrm{C}_{1 \mathrm{~s}}$ peak and $\mathrm{N}_{1 \mathrm{~s}}$ peak. The results strongly suggest that the surface of the magnesium plate was coated with hexyl- or phenethyl-urea silane. Surface chemical modification of the copper cluster deposition on magnesium surface was carried out by forming a SAM of organosilane derivatives. After coating the surface with urea silane derivatives, the water contact angle increased considerably; the presence of hydrophobic molecules on the surface is proof of the increase in the contact angle. The methyl-terminated or phenyl-terminated hydrocarbon groups shield the polar metal clusters deposited on the surface, and the urea group in the silane derivatives effectively connects the molecules in the SAMs.

\section{Conclusion}

In this study, we synthesized hexyl- and phenethyl-urea silanes and used them in the fabrication of superhydro-

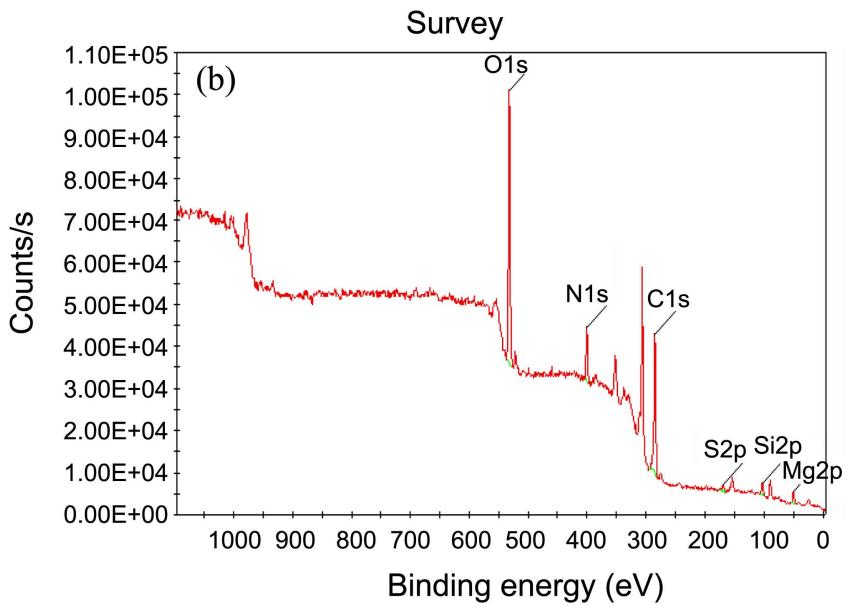

Figure 7. (a) XPS pattern of hexyl-urea silane coating on $\mathrm{Cu}$ deposited $\mathrm{Mg}$ surface. (b) XPS pattern of phenethyl-urea silane coating on $\mathrm{Cu}$ deposited Mg surface. 
phobic surfaces on cupper deposited magnesium plates. This method is simple and cheap; in addition, the superhydrophobic surfaces obtained were stable over a wide range of $\mathrm{pH}$ values. Thus, the silane derivatives synthesized in this study can serve as suitable alternatives to low surface energy materials such as fluorinated alkyl silane derivatives used in the fabrication of superhydrophobic surfaces.

Acknowledgments. This work was supported by the GRRC program of Gyeonggi province, 66966, Preparation and UV curing characteristics of Silicone Modified Acrylate for Flexible Substrate Hard Coating.

\section{References}

1. Sun, T.; Feng, L.; Gao, X.; Jiang, L. Acc. Chem. Res. 2005, 38, 644.

2. Blossey, R. Nature Materials 2003, 2, 301.

3. Shi, M.; Xi, J.; Wang, H.; Wu, X.; Adhes, J. Sci. Technol. 2008, 22,311 .

4. Reetz, M. Adv. Mater. 1997, 9, 943.

5. Tadanaga, K.; Morinaga, J.; Minami, T. J. Sol-Gel Sci. Tech. 2000, $19,211$.
6. Pilotek, S.; Schmidt, H. J. Sol-Gel Sci. 2003, 26, 789.

7. Fu, X.; He, X. Appl. Surf. Sci. 2008, 255, 1776.

8. Liang, J.; Guo, Z.; Fang, J.; Hao, J. Chem. Lett. 2007, 36, 416.

9. Wang, Q.; Hou, W.; Zhang, Y. Appl. Surf. Sci. 2009, 256, 664.

10. Su, C. Appl. Surf. Sci. 2010, 256, 2122.

11. Levkin, P.; Svec, F.; Frechet, J. Adv. Funct. Mater. 2009, 19, 1.

12. Yuan, Z.; Chen, H.; Tang, J.; Zhao, D. J. Appl. Polymer Sci. 2009, $113,1626$.

13. Erbil, H.; Demirel, A.; Avcl, Y.; Mert, O. Science 2003, 299, 1377.

14. Hang, T.; Hu, A.; Ling, H.; Li, M.; Mao, D. Appl. Surf. Sci. 2010 , 256,2400 .

15. Yasseri, A.; Kobayashi, N.; Kamins, T. Appl. Phys. A 2006, 84, 1.

16. Nishino, T.; Meguro, M.; Nakamae, K.; Matsushita, M.; Ueda, Y. Langmuir 1999, 15, 4321.

17. Fadeev, A.; McCarthy, T. Langmuir 2000, 16, 7268.

18. Yasseri, A.; Sharma, S.; Kamins, T.; Xia, Q.; Chou, S.; Pease, R. Appl. Phys. Lett. 2006, 89, 153.

19. Kulinich, S.; Farzaneh, M. Appl. Surf. Sci. 2004, 230, 232.

20. Zhang, X.; Shi, F.; Yu, X.; Liu, H.; Fu, Y.; Wang, Z.; Jiang, L.; Li, X. J. Am. Chem. Soc. 2004, 126, 3064.

21. Shustak, G.; Domb, A.; Mandler, D. Langmuir 2004, 20, 7499.

22. Chen, L.; Chen, M.; Zhou, H.; Chen, J. Appl. Surf. Sci. 2008, 255, 3459.

23. Kulinich, S.; Farzaneh, M. Surf. Sci. 2004, 573, 379.

24. Shirtcliffe, N.; Mchale, G.; Newton, M.; Perry, C. Langmuir 2005 $21,937$. 